\title{
DAMAGE EVOLUTION LAW BASED ON ACOUSTIC EMISSION AND WEIBULL DISTRIBUTION OF GRANITE UNDER UNIAXIAL STRESS
}

\author{
Ming JI ${ }^{1)}$, Yi-Dong ZHANG ${ }^{2) *}$, Wen-Peng LIU ${ }^{3)}$ and Liang CHENG ${ }^{1)}$

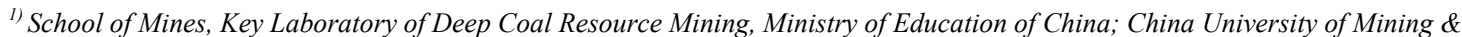 \\ Technology, Xuzhou, 221116, China \\ 2) State Key Laboratory of Coal Resources and Safe Mining, School of Mines, China University of Mining \& Technology, \\ Xuzhou, Jiangsu, 221116, China \\ ${ }^{2)}$ School of Civil and Resource Engineering; University of Western Australia, Perth, Western Australia, 6009, Australia \\ *Corresponding author's e-mail: ydzhang@cumt.edu.cn
}

\begin{tabular}{l} 
ARTICLE INFO \\
\hline Article history: \\
Received 29 August 2013 \\
Accepted 1 April 2014 \\
Available online 20 May 2014 \\
\hline
\end{tabular}

Keywords:

Granite

Acoustic emission technique

Weibull distribution

Damage evolution

Constitutive equation

\section{ABSTRACT}

The research on rock damage mechanisms during loading has a significant reference value for the deformation damage issues in the rock engineering industry. In this paper, Electrohydraulic Servo Material Test System MTS815 and PCI-2 based AE System were utilized for uniaxial compression tests of granite specimens and acoustic emission monitoring tests during the compression respectively. According to the test data, there is a well defined correspondence between the curves of acoustic emission count rate with time and stress-strain curves of rock. Moreover, from the stress-strain curves, the characteristics of brittle fracture have been showed. Four stages were identified, namely compression stage, linear elastic stage, weakening stage and failure stage. There are also four stages in acoustic emission count rate with time curves: quiet period, slow growth period, intense growth period and attenuation period. Based on the acoustic emission data and the Weibull distribution, two different damage variables were derived describing the damage evolution of rock during loading. In addition, the corresponding constitutive equations have been deduced. The conclusions of this paper can provide references for the issues of the rock deformation and the damage during loading.

\section{INTRODUCTION}

Deformation of rock is one of the significant aspects of rock mechanical properties; researchers have done a lot of efforts on it. Moreover, many researchers tried to explain the relationships between loading and deformation of rock (Cook, 1965; Bieniawski, 1967 a, b, c; Hoek, 1968; Brady, 1969 a, b).

With the development of damage mechanics, the study on damage evolution law and failure mechanisms of rock was successfully used to deal with the constitutive response of rock. And many constitutive models considering of damage mechanics for brittle or ductile materials have been proposed.

Micro-damage mechanics is based on molecules and atoms to research physical processes in materials. It uses the methods of quantum mechanics and statistical mechanics to confirm effects of damages on micro-structures; then, their macro-mechanical effects can be speculated (Budiansky, 1983).

Mesodamage mechanics studies forms, distributions and evolution features of different damages from meso structures, such as granules, crystals and holes. Then, it can predict the macromechanical characteristics of materials. One aspect of meso damage mechanics mainly focuses on the quantitative relationships between meso damage structures and mechanical parameters. For example,
Gurson et al. (1977) predicted the matrix is a rigidplastic body with the presence of holes or voids and used analytical methods to conduct a systematic study for the model. Nemat-Nasser et al. (Horii et al., 1983; Nemat-Nasser et al., 1988) assumed the matrix as an isotropic elastic body; then, used analytical methods to find a model for this matrix which confirmed the presence of cracks within the structure. Ju and Lee (1991) and Lee and Ju (1991) used analytical methods to find a model with cracks in the anisotropic brittle elastic body. Bazant (1988, 1990) applied micro-plane theory to build the model of damage in materials. Statistical physics theory is one of the popular methods which are applied for the study on the evolution and the development of meso-damage (Statistical meso damage mechanics) (Weibull, 1939). For most materials, the strength to brittle fracture is different from one specimen to another. That is because of disorder within the materials. For this situation, Sahimi et al. (Sahimi et al., 1993) mentioned the strength theory of the weakest link of materials and Weibull statistical hypothesis. Moreover, Yang (1999) and Caoet al. (1998) used the Weibull statistical hypothesis for the foundation of rock damage constitutive models.

Based on the theory of continuum mechanics and irreversible thermodynamics, macro damage mechanics (CDM) assumes that the media, which 
contains various defects and structures, is a continuum. Moreover, the damage is described as continuous distribution by an average variable. The level of damage is described by a damage variable. With the conditions of basic postulates and theorems of mechanics and thermodynamics, the constitutive equations of damage body and damage evolution equations can be derived. During the process of CDM foundation, the damage constitutive and the damage evolution equations can be confirmed from free energy functions and damage functions respectively. Thus, the derivation of free ratio energy functions and damage functions is required. Many researchers around the world established different continuum damage mechanics models. For example, Marigo (1985) and Krajcinove (1983) considered the effects of strain on the level of damage when establishing a model. Moreover they derived the functions of free ratio energy. Rousselier (1981) established free ratio energy functions and damage functions with smaller elastic strain performance. Simo et al. (1987) reported elastic-plastic damage models based on the stress and the strain separately. Moreover, he established free energy functions and damage yield functions based on the strain. With the research on rock micro-fracture mechanisms and rock creep damage theory, Xie (Xie, et al., 1991; Xie, 1994) combined damage with the finite element analysis of rock creep large deformation to study on the relative issues of rock damage. Xie et al. introduced fractal geometry in relation to the micro-damages and the macro-fractures in rock.

Using damage theory to study materials such as rock under loading, how to definite the damage variables and damage evolution mechanisms are the first key step. Then, the next step is how to correctly confirm constitutive equations that calculate the damage variables and damage evolution law. The description of damages and their evolution is given by damage variables. Thus, the definition of damage variables is of a primary importance.

The acoustic emission technique is used to study the mechanical properties and the damage mechanisms in granite. Spasova et al. (2012) focused on melting and solidification of natural granite studied by acoustic emission method. Jianget al. (2013) studied the mechanical properties of salt rock by acoustic emission tests. Chmel et al. (2013) studied the impact fracture of granite by acoustic emission tests. Maet al. (2012), Ai et al. (2012) and Yin et al. (2012) studied the mechanical properties of coal samples under uniaxial compression and triaxial compression by the acoustic emission technique.

Uniaxial compression experiments on granite samples and acoustic emission monitoring and data analysis have be conducted. Using the acquired data, various damage variables were selected to analyze the damage evolution of rock; then, derive the corresponding constitutive equations.

\section{EXPERIMENT METHOD}

\subsection{SAMPLE PREPARATION}

The density of the granite used in these experiments is $2.7 \mathrm{~g} / \mathrm{cm}^{3}$ and the average uniaxial compressive strength is $185 \mathrm{MPa}$. The granite has been cut into cylinders with a diameter-height ratio of $1: 2$, the diameter is $25 \mathrm{~mm}$. Its main components are feldspar, pyroxene and illite.

\subsection{EQUIPMENT}

Loading equipment: Electro-hydraulic Servo Material Test System MTS815 with automatic data recording for deformation and other related data. The system MTS815 was set in a loading mode with displacement control and a loading speed of $0.0015 \mathrm{~mm} / \mathrm{s}$.

Acoustic Emission Monitoring System: PCI-2 based AE system supplied by PHYSICAL ACOUSTICS. A 18 bit analog-to-digital converter was used to digitize the analogue acoustic sensor signal. The acoustic emission data flow monitor in PCI-2 can monitor and store the real-time data on a PC.

Acoustic emission sensors: the resonance frequency of the acoustic emission sensors used in these experiments is $140 \mathrm{kHz}$.

\subsection{CONFIGURATION SETTINGS FOR ACOUSTIC EMISSION DATA ACQUISITION}

(1) Based on the environment noise level of the experiments, the noise detection threshold was set up at $40 \mathrm{~dB}$. The following data acquisition parameters were set: peak definition time(PDT) at $50 \mu \mathrm{s}$, hit definition time(HDT) at $200 \mu s$, hit lock-out time(HLT) at $300 \mu \mathrm{s}$. Suitable setting of the PDT guarantees the correct recognition of signal peak for rise time measurements. A proper HDT value ensures that a single signal hit is recorded as only one hit. The HLT closes out the measurement process and stores the hit waveform quantification parameters (amplitude, counts, energy, and so on) in the data acquisition buffer. The sampling frequency was $500 \mathrm{kHz}$.

(2) The samples and the acoustic emission sensors were coupled by Vaseline.

(3) Rock samples are loaded until failure.

\section{ANALYSIS OF MECHINICS AND ACOUSTIC PROPERTIES}

\subsection{ANALYSIS OF GRANITE MECHANICAL PROPERTIES}

The stress-strain curves obtained from experiments are included in Figure 1.

The stress-strain curves in Figures $1 \mathrm{a}$ and $1 \mathrm{~b}$ can be divided into four stages: compression stage(OA), linear elastic stage(AB), weakening stage(BC) and failure stage $(\mathrm{CD})$.

During the first stage, the existing cracks in the granite samples close, thus the stress increases slowly 


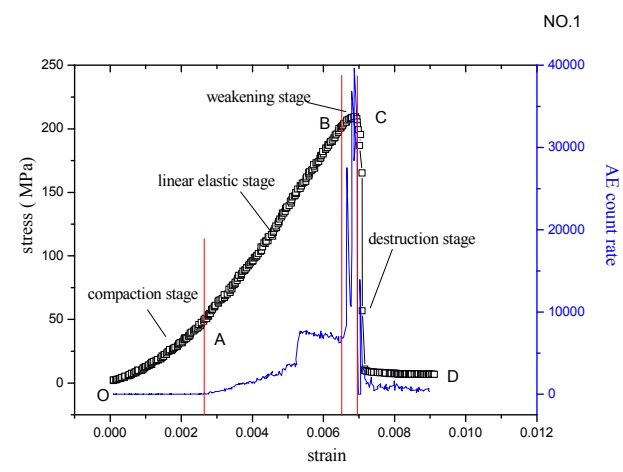

(a) Sample NO.1

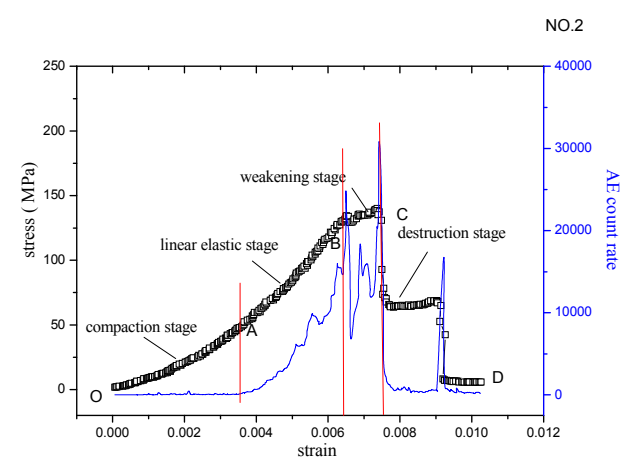

(b) Sample NO.2

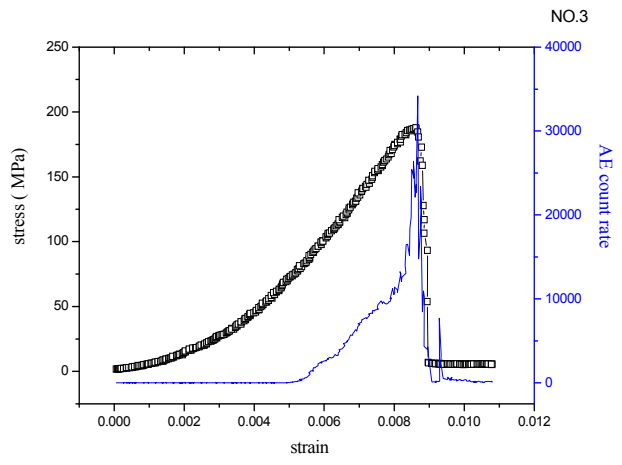

(c) Sample NO.3

Fig. 1 The stress-strain curves and AE data of granite under uniaxial compression.

but the strain increases significantly as represented by the stress-strain curves in Figure 1.

The linear section of the stress-strain curve corresponds to the granite transition from the compression stage to the linear elastic stage. This occurs prior to the applied peak load.

Prior to the applied peak load, the relation between stress and strain becomes non-linear. This indicates the granite transition under load from the linear elastic stage to the weakening stage.

Finally, the granite fractures suddenly and the stress drops to a residual stress level indicating that the sample has brittle failure characteristics.

\subsection{ANALYSIS OF ACOUSTIC EMISSION DATA}

The acoustic emission characteristics acquired during the uniaxial compression tests with the granite are shown in Figure 1.

From the graphs, the acoustic emission count rate (the count of pulse signal exceeded the detection threshold in unit time) plots can be divided into the following stages: inactivity period, slow growth period, rapid growth period and attenuation period.

The quite period of the acoustic emission count rate corresponds to the compression stage of the stress-strain curve. The absence of any important acoustic emission signals or visible damage during this initial period of loading indicates closure of existing micro cracks within the granite samples. Similarly, the slow growth period corresponds to the linear elastic stage in the stress-strain curves. Acoustic emission activity and internal damage initially occur during this stage. The rapid growth period in the acoustic emission count rate corresponds to the weakening and the initial damage stages of the stressstrain curve. After this period, the measured stress dropped to residual stress levels as a result of specimen failure. Since of energy is accumulated during the previous stages of loading, the microcracks are propagating. Energy is transiently released resulting in increased acoustic emission count rates. When the microcracks grow to macrocracks, the structure yields, the stress decreases from the peak value, and the accumulated energy is released in the form of acoustic emission. The last attenuation period is consistent with the late damage stage of stress-strain curve or residual stress stage. When the sample was destroyed, the energy released and the recorded acoustic emission count lowered to the levels from the initial loading stage.

The stress-strain curve of sample NO. 2 is different from the stress-strain curves of the other two samples. Sample NO. 2 was characterized by larger plastic deformation demonstrated by the stress-strain 


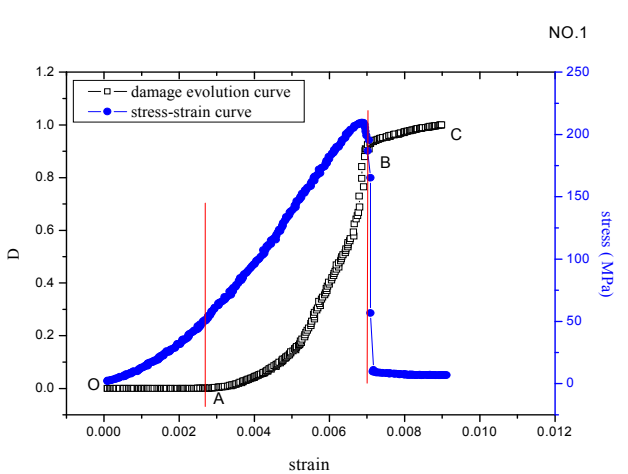

(a) Sample NO.1

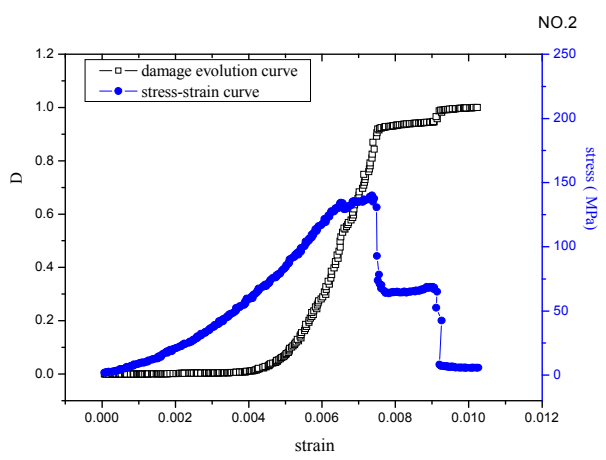

(b) Sample NO.2

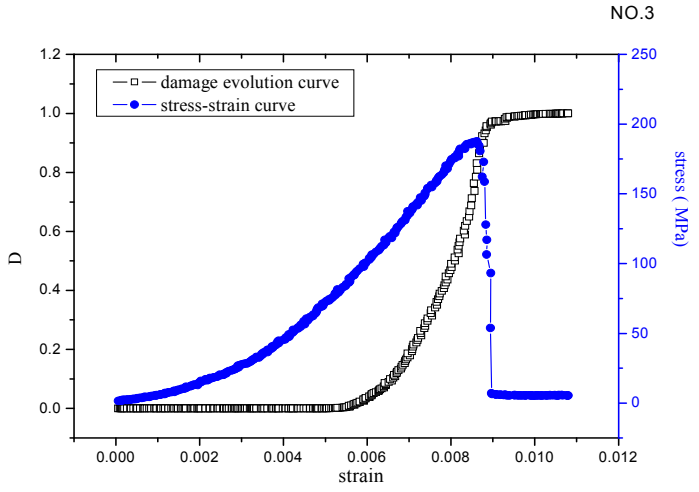

(c) Sample NO.3

Fig. 2 Damage evolution law by AE of uniaxial compressed granite.

curve. The curve of acoustic emission count rate also showed a number of smaller peak count rates during the weakening stage and the failure stage of sample NO. 2.

\section{DAMAGE EVOLUTION LAW UNDER UNIAXIAL STRESS \\ 4.1. DAMAGE EVOLUTION LAW BASED ON ACOUSTIC EMISSION}

Damage variable, $\mathrm{D}$, is used to quantify the level of structural damage. As acoustic emission is caused by internal cracks and micro cavities evolving and developing within a structure during loading, the acoustic emission count rate could be used as a statistical parameter to characterize the evolution of the granite damage. Tang et al. (1990) proposed a damage variable that is associated with the measured acoustic emission amplitude. Zhang et al. (2006) reported a relation between the acoustic emission and the damage variable D as:

$D=\frac{\Omega}{\Omega_{m}}$

where $\Omega_{m}$ is a cumulative number of an acoustic emission parameter such as hits, counts, amplitudes or energies determined when the sample is destroyed and $\Omega$ is the cumulative number of the same acoustic emission parameter during damage extent, and $0 \leq \Omega \leq \Omega_{m}$, or $0 \leq D \leq 1$.
Graphical representations of the stress-strain and damage-strain relations for the three granite samples, as determined by the damage variable $\mathrm{D}$ from formula (1), are shown in Figure 2:

The plots for sample NO.1 in Figure 2 can be divided into three stages: a) segment OA corresponding to the compression phase of the stressstrain curve and the quite period of the acoustic emission counts rate where the damage value is less than $0.1, b)$ segment $A B$ representing the linear elastic stage and the weakening stage before failure and the slow growth period and rapid growth period in the acoustic emission count rate and c) the final segment $\mathrm{BC}$ corresponding to the damage stage in the stressstrain curve and the attenuation period of the recorded acoustic emission. According to the analysis above and considering the continuity of damage evolution, damage evolution law can be described as:

$D=\left\{\begin{array}{l}0, \varepsilon \leq \varepsilon_{a} \\ c_{1}\left(e^{\frac{\varepsilon_{b}-\varepsilon_{a}}{c_{2}}}-1\right), \varepsilon_{a}<\varepsilon \leq \varepsilon_{b} \\ c_{3}+c_{4} \varepsilon, \varepsilon_{b}<\varepsilon \leq \varepsilon_{c}\end{array}\right.$

where

$c_{3}=c_{1}\left(e^{\frac{\varepsilon_{b}-\varepsilon_{a}}{c_{2}}}-1\right)-\frac{1-c_{1}\left(e^{\frac{\varepsilon_{b}-\varepsilon_{a}}{c_{2}}}-1\right)}{\varepsilon_{c}-\varepsilon_{b}} \varepsilon_{b} ;$ 


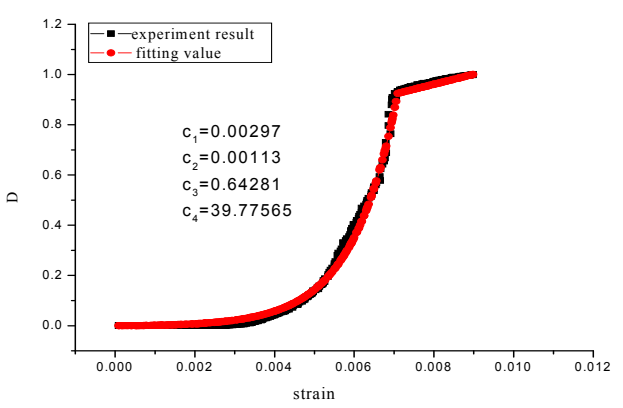

(a) Sample NO.1

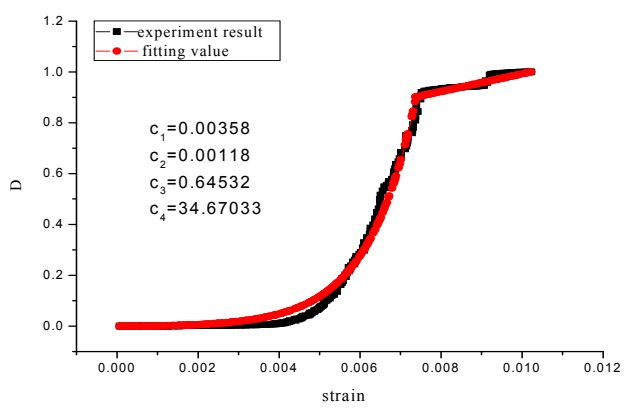

(b) Sample NO.2

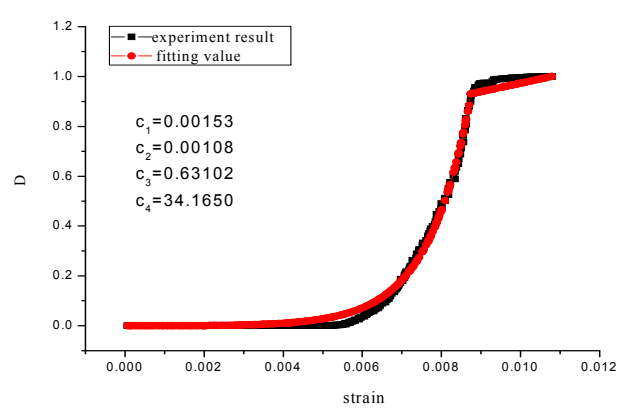

(c) Sample NO.3

Fig. 3 Damage evolution curves of the experimental and fitting value by AE under uniaxial stress.

$c_{4}=\frac{1-c_{1}\left(e^{\frac{\varepsilon_{b}-\varepsilon_{a}}{c_{2}}}-1\right)}{\varepsilon_{c}-\varepsilon_{b}}$

$\varepsilon_{a}$ - strain value at the end of compression phase;

$\varepsilon_{b}$ - residual strain;

$\varepsilon_{c}$ - strain value at failure.

The damage evolution law given by formula (2) is a suitable approximation of the physical properties of the tested granite samples with a correlation coefficient exceeding 0.9. Therefore, granite damage evolution law based on acoustic emission under uniaxial stress can be described by formula (2). Figure 3 illustrates the correlation of the physical data and the calculated damage variable from the damage evolution law for the three granite samples.

\subsection{DAMAGE EVOLUTION LAW BASED ON \\ WEIBULL DISTRIBUTION}

The growth of microcracks in granite is random; hence the micro damage evolution process is stochastical and follows a Weibull distribution (Weibull W., 1939). The distribution density function is given as:

$$
\phi(F)=\frac{m}{F_{0}}\left(\frac{F}{F_{0}}\right)^{m-1} \exp \left[-\left(\frac{F}{F_{0}}\right)^{m}\right]
$$

where $F$ is the random distribution variable of the Weibull distribution, $m$ is the brittle distribution parameter, and $F_{0}$ is the macro average strength distribution parameter. $\phi(F)$ determines the damage rate of micro-unit. Micro-unit damage accumulation results in macro damage.

Damage degree indicates the quantity of microunit defects which directly influences micro-unit strength; therefore, relation between damage parameter $D$ and probability density of micro-unit damage is described by formula (4):

$\frac{d D}{d F}=\phi(F)$

Integration of formula (4) gives:

$D=\int_{0}^{F} \phi(F) d F=1-\exp \left[-\left(\frac{F}{F_{0}}\right)^{m}\right]$

Damage criterion of granite is subject to Druckr Prager yield criteria, and the micro-unit strength can br expressed as:

$F=f(\sigma)=\alpha I_{1}+J_{2}^{1 / 2}$

where: $I_{1}=\sigma_{1}+\sigma_{2}+\sigma_{3}$,

$J_{2}=\frac{1}{6}\left[\left(\sigma_{1}-\sigma_{2}\right)^{2}+\left(\sigma_{2}-\sigma_{3}\right)^{2}+\left(\sigma_{3}-\sigma_{1}\right)^{2}\right]$,

$\alpha=\frac{\tan \phi}{\left(9+12 \tan ^{2} \phi\right)^{1 / 2}}, \sigma_{1} \sigma_{2} \sigma_{3}$ are three principal

stresses, $\varphi$ is the internal friction angle of rocks. 


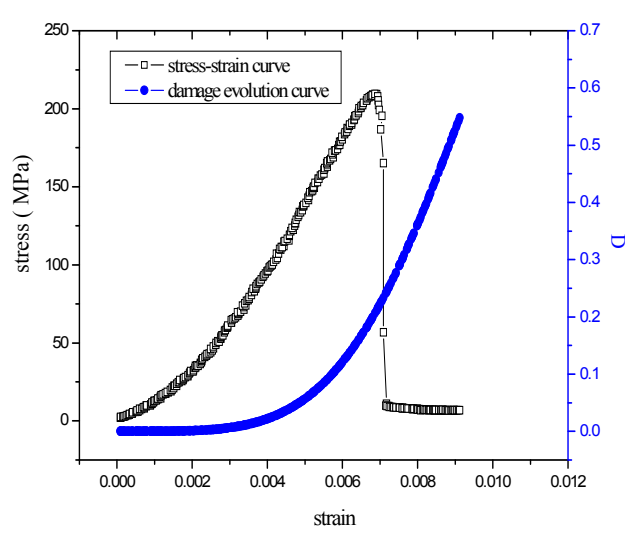

(a) Sample NO.1

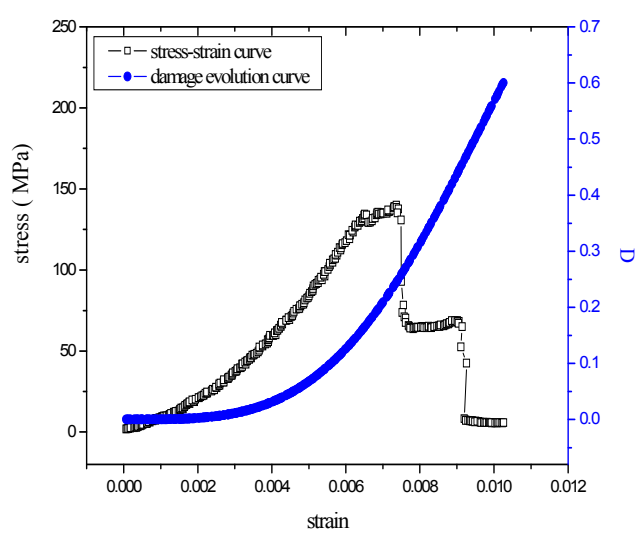

(b) Sample NO.2

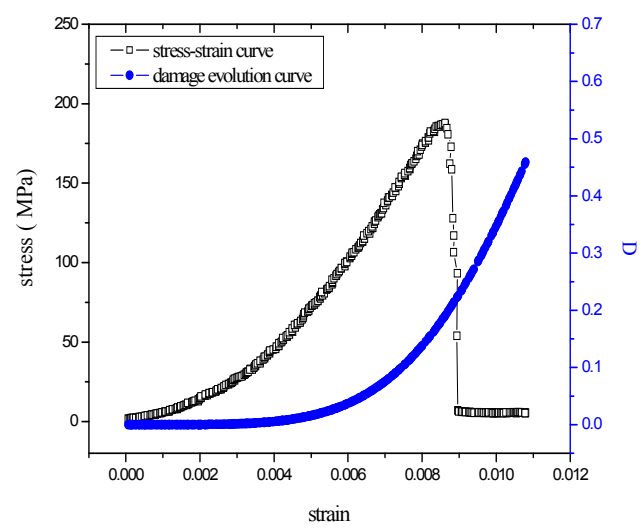

(c) Sample NO.3

Fig. 4 Granite damage evolution curve based on Weibull distribution under uniaxial compression.

Lemaitre's hypothesis for equivalent strain proposes a constitutive relation based on statistical damage that can be expressed as (Lemaitre, 1984):

$$
\sigma^{*}=\frac{\sigma}{1-D}
$$

where $\sigma^{*}$ is the effective stress and $\sigma$ is the nominal stress measured in the experiments.

A damage constitutive relation of granite is derived on the basis of equivalent strain hypothesis (Lemaitre, 1984.) as:

$$
\sigma=E_{0} \varepsilon(1-D)
$$

where $E_{0}$ is the elastic modulus of the material.

The uniaxial load applied means that $\sigma_{1}=\sigma^{*}$ and formula (6) can be rewritten as follows:

$$
F=\left(\alpha+\frac{1}{\sqrt{3}}\right) \frac{\sigma}{1-D}
$$

After substituting formula (8) into formula (9) the result is:

$$
F=\left(\alpha+\frac{1}{\sqrt{3}}\right) E_{0} \varepsilon
$$

With substituting formula (5) and (10) into formula (8):

$\sigma=E_{0} \varepsilon \exp \left\{-\left[\frac{\left(\alpha+\frac{1}{\sqrt{3}}\right) E_{0} \varepsilon}{F_{0}}\right]^{m}\right\}$

$\frac{d \sigma}{d \varepsilon}=E_{0} \mathrm{e}^{-\left[\frac{\left(\alpha+\frac{1}{\sqrt{3}}\right) E_{0} \varepsilon}{F_{0}}\right]^{m}}\left\{1-m\left[\frac{\left(\alpha+\frac{1}{\sqrt{3}}\right) E_{0} \varepsilon}{F_{0}}\right]^{m}\right\}$

When the strain reaches peak stress point in uniaxial compression curve, $\left.\frac{d \sigma}{d \varepsilon}\right|_{\varepsilon=\varepsilon_{d}}=0, \varepsilon_{d}$ is strain value at peak stress and

$$
F_{0}=\left(\alpha+\frac{1}{\sqrt{3}}\right) E_{0} \varepsilon_{d} m^{1 / m}
$$




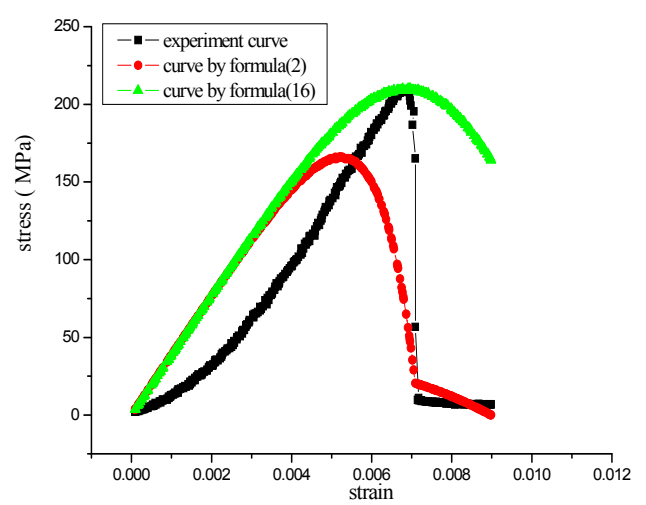

(a) Sample NO.1

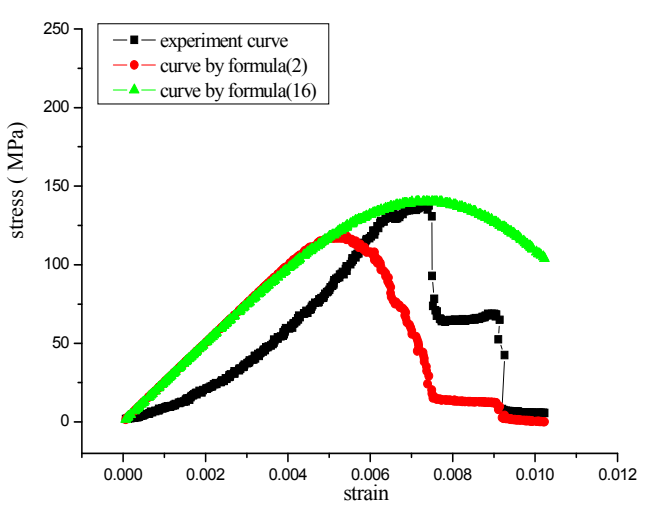

(b) Sample NO.2

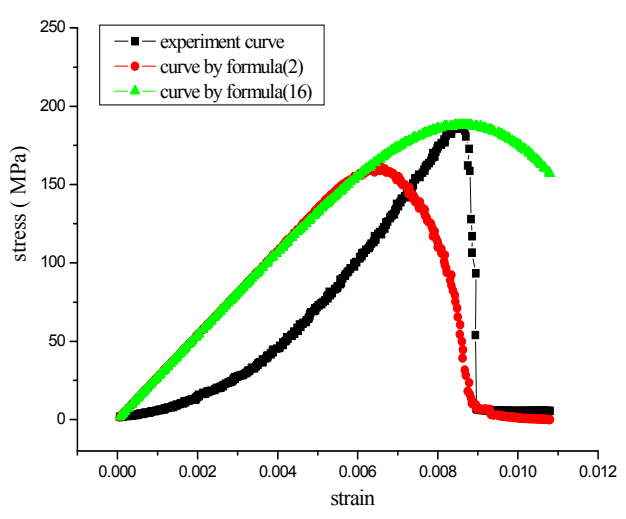

(c) Sample NO.3

Fig. 5 Uniaxial stress-strain curves of granite.

Then equation (11) can be re-written as

$$
m=\frac{1}{\ln \left(E_{0} \varepsilon_{d}\right)-\ln \sigma_{\max }}
$$

The uniaxial compression constitutive equation is derived using formulas (13) and (14) as:

$$
\sigma=E_{0} \varepsilon \mathrm{e}^{-\frac{1}{m}\left(\frac{\varepsilon}{\varepsilon_{d}}\right)^{m}}
$$

On the basis of equation (9) and (15) the mechanical damage caused by loading of the granite can be quantified as:

$$
D=1-\mathrm{e}^{-\frac{1}{m}\left(\frac{\varepsilon}{\varepsilon_{d}}\right)^{m}}
$$

The damage evolution curves calculated from formula (16) for the three granite samples are shown in Figure 4.

\subsection{ROCK CONSTITUTIVE EQUATION}

By substituting the two different damage variables shown in equations (2) and (16) into equation (8), the resulting stress-strain experimental curve and theoretical constitutive curve are shown in Figure 5.
Comparing experimental data with the theoretical analysis draws the following conclusions:

(1) Both theoretically calculated curves describe the brittle failure in granite. The mechanical strength of the granite samples is characterized by linearly elasticity region followed by a sudden loss of strength after the peak stress value.

(2) Neither of the two theoretically calculated curves can reflect the compression stage of the experimental stress-strain profile. The calculated stress values are larger than the experimental stress values before the peak stress is attained at the same strain value. Therefore, the damage parameter requires further modifications to improve accuracy.

(3) The peak stress value obtained from the damage acoustic emission constitutive equation is lower than the experimental peak stress. Furthermore, the former occurs earlier in the stress-strain profile than the latter.

(4) The derived damage constitutive equation based on Weibull distribution follows the experimental stress-strain dependence up to peak load. However, the post-peak stress profile significantly differs from the experiment data. 
The two approaches of theoretical analysis presented in this paper could reflect certain characteristics of the uniaxial stress-strain curves for the three granite samples. The inconsistency between the theoretical calculated damage value and the actual damage value needs further investigation by introducing discrete damage parameter points and increasing the reliability of collecting experimental data.

\section{CONCLUSION}

In this paper the mechanical properties of granite were studied under uniaxial compression with the acoustic emission technique. The following conclusions can be drawn:

(1) The acoustic emission count rate versus time plot correspond to the stress-strain curve and can be divided into four stages; quite period, slow growth period, rapid growth period and attenuation period.

(2) Two damage evolution laws were studied. Both of them can describe but with limitations the failure process of granite.

(3) Two constitutive damage equations were derived on the basis of the acoustic emission experiments and Weibull distribution. However, the derived damage parameter equation needs further modification in order to optimize the theoretical model.

\section{ACKNOWLEDGEMENT}

This paper is supported by "Natural Science Foundation of Jiangsu Province, China (Grant No.BK20130189), "Priority Academic Program Development of Jiangsu Higher Education Institutions", "The Fundamental Research Funds for the Central Universities (2011QNA12)", "The Postdoctoral Foundation of Jiangsu Province (1101033C)" and "Funded by the Open Projects of State Key Laboratory of Coal Resources and Safe Mining, CUMT (SKLCRSM12X05)". Appreciate for the help and guidance of Xiao-Li XU and the United States Senior Engineer Scott for this research.

\section{REFERENCES}

Ai, T., Zhang, R., Liu, J.F. and Ren, L.: 2012, Space-time evolution rules of acoustic emission location of unloaded coal sample at different loading rates. International Journal of Mining Science and Technology, No. 22, 847-854. DOI: $10.1016 /$ j.ijmst.2012.12.001

Bazant, Z.P. and Ozbolt, J.: 1990, Nonlocal micro plane model for fracture, damage and size effect in structures, Journal of Engineering Mechanics, No. 116(11), 2485-2505.

Bazant, Z.P. and Prat, P.C.: 1988, Micro-plane model for brittle plastic material, Part I: Theory, Part II : Verification Journal of Engineering Mechanics., ASCE, No. 114, 1672-1702.

Bieniawski, Z.T.: 1967a, Mechanism of brittle fracture of Rock: Part I-Theory of the fracture process. International Journal of Rock Mechanics and Mining
Sciences \& Geomechanics Abstracts, No.4 (4), 395406.

Bieniawski, Z.T.: 1967b, Mechanism of brittle fracture of Rock: Part II-Experimental studies. International Journal of Rock Mechanics and Mining Sciences \& Geomechanics Abstracts, No. 4 (4), 407-423.

Bieniawski, Z.T.: 1967c, Mechanism of brittle fracture of Rock: Part III-Fracture in tension and under long-term loading. International Journal of Rock Mechanics and Mining Sciences \& Geomechanics Abstracts, No. 4 (4), 425-430.

Brady, B.T.: 1969a, The nonlinear mechanical behavior of brittle rock: Part I-stress-strain behavior during regions I and II. International Journal of Rock Mechanics and Mining Sciences \& Geomechanics Abstracts, No. 6 (2), 211-225.

Brady, B.T.: 1969b, The nonlinear mechanical behavior of brittle rock: Part II-stress-strain behavior during regions III and IV. International Journal of Rock Mechanics and Mining Sciences \& Geomechanics Abstracts, No. 6 (3), 301-310.

Budiansky, B.: 1983, Micromechanics Advances and Trens in Structural and Solid Mechanics, (Eds: Noor A. K., Housner J. M.) Pergamon Press, 3-12.

Cao, W.G., Fang, Z.L. and Tang, X.J.: 1998, Statistical studies of rock damage softening constitutive models. Chinese Journal of Rock Mechanics and Engineering, No.17(6), 628-633.

Cook, N.G.W.: 1965, The failure of rock. International Journal of Rock Mechanics and Mining Sciences \& Geomechanics Abstracts, No. 2 (4), 389-403. DOI: $10.1115 / 1.3167044$

Gurson, A.L.: 1977, Continuum theory of Duetile rupture by void nucleation and growth, Part 1-yield criteria and flow rules for porous ductile media. Transactions of the ASME. Series H, Journal of Engineering Materials and Technology. No. 99: 2-15.

Hoek, E.: 1968, Brittle failure of rocks in rock mechanics in engineering practice. In: Stagg, K.G., Zienkiewicz, O.C. (Eds.), Rock Mechanics in Engineering Practice. Wiley, New York, 99-124.

Horii, H. and Nemat-Nasser, S.: 1983, Overall moduli of solids with microcracks: Load-induced anisotropy. Journal of the Mechanics and Physics of Solids, No. 31, 315-330.

Chmel, A. and Shcherbakov, I.: 2013. A comparative acoustic emission study of compression and impact fracture in granite. International Journal of Rock Mechanics and Mining Science, No. 64, 56-59. DOI: 10.1016/j.ijrmms.2013.08.025

Jiang, D.Y., Chen, J., Ren, S., Xi, Y. and Yang, C.H.: 2013, A damage constitutive model of rock salt based on acoustic emission characteristics, Clean Energy Systems in the Subsurface: Production, Storage and Conversion, Proceedings of the 3rd Sino-German Conference "Underground Storage of $\mathrm{CO}_{2}$ and Energy", Goslar, Germany, 363-377. DOI:10.1007/978-3-642-37849-2_29

Ju, J.W. and Lee, X.: 1991, Micromechanical Damage Models for Brittle Solids, Part I: Tensile loadings. Journal of Engineering Mechanics, No. 117(7), 14951514.

DOI: 10.1061/(ASCE)0733-9399(1991)117:7(1495)

Krajcinovic, D.: 1983, Constitutive equation for damaging materials. Journal of Applied Mechanics, No. 50, 355360 . 
Lee, X. and Ju J.W.: 1991, Micromechanical Damage Models for Brittle Solids, Part II : Compressive loadings. Journal of Engineering Mechanics, No. 117(7), 1515-1536.

DOI: 10.1061/(ASCE)0733-9399(1991)117:7(1515)

Lemaitre, J.: 1984, How to use damage mechanics. Nuclear engineering and design, No. 80, 233-245.

Ma, Y.K., Wang, E.Y., Xiao, D., Li Z.H., Liu, J. and Gan, L.J.: 2012, Acoustic emission generated during the gas sorption-desorption process in coal. International Journal of Mining Science and Technology, No. 22, 391-397. DOI: 10.1016/j.jimst.2011.11.001

Marigo, J.: 1985, Modelling of brittle and fatigue damage for elastic material by growth of microvoids. Engineering Fracture Mechanics, 21(4), 861-874.

Nemat-Nasser, S. and Obata, M.: 1988, A Microcrack model of dilatancy in brittle materials. Transaction of the ASME, No. 55, 24-35.

Rousselier, G.: 1981, Finite deformation constitutive relations including ductile fracture damage. Threedimensional constitutive relations and ductile fracture, (Eds: Nemat-Nasser, S.), North-Holland Publishing Company.

Sahimi, M.and Arbabi, S.: 1993, Mechanics of disordered solids. Physical Review B, No. 47, 713-722. DOI:http://dx.doi.org/10.1103/PhysRevB.47.713

Simo, J.C. and Ju, J.W.: 1987, Strain-and stress-based continuum damage models, Part I: Formulation. International Journal of Solid and Structures, No. 23(7), 821-840. DOI: 10.1016/0020-7683(87)90083-7

Simo, J.C. and Ju, J.W.: 1987, Strain-and stress-based continuum damage models, Part II : Computational aspects. International Journal of Solid and Structures, No. 23(7), 841-869.

DOI: $10.1016 / 0020-7683(87) 90084-9$
Spasova, L.M, Ojovan, M.I and Gibb, F.: 2012, Acoustic emission on melting/solidification of natural granite simulating very deep waste disposal. Nuclear engineering and design, No. 248,329-339. DOI: 10.1016/j.nucengdes.2012.03.024

Tang, C.A. and Xu, X.H.:1990, Evolution and propagation of material defects and Kaiser effect function. Journal of Seismological Research, No. 13(2), 203-213.

Weibull, W.: 1939, A Statistical theory of the strength of materials. Royal Swedish of Institute for Engineering Research, No. 151(15), 1-45.

Xie, H.P. and Gao, F.: 1991, Fractal characteristics of rock material damage evolution. Chinese Journal of Rock Mechanics and Engineering, No. 10(1), 74-82.

Xie, H.P., Sanderson, D.J. and Peacock, D.C.P.: 1994, A fractal model and energy dissipation for an Echelon fractures. Chinese Journal of Geotechnical Engineering, No. 16 (1), 1-7. DOI: 10.1016/0013-7944(94)90173-2

Yang, Y.Q.: 1999, Damage mechanics analysis of rock strength. Chinese Journal of Rock Mechanics and Engineering, 23-27.

Yin, G.Z., Qin, H., Huang, G., Lu, Y.C. and Dai, Z.X.:2012, Acoustic emission from gas-filled coal under triaxial compression. International Journal of Mining Science and Technology, No. 22,775-778. DOI:10.1016/j.ijmst.2012.11.005

Zhang, M., Li, Z.K., Yang, Q and Feng, X.T.: 2006, A damage model and statistical analysis of acoustic emission for quasi-brittle materials. Chinese Journal of Rock Mechanics and Engineering, No. 25(12), 2493-2501. 